\title{
Seismic evaluation and studying the effect of friction damper
}

\author{
Mahmood Miri, Aidin Kahkeshan* \\ Department of Civil Engineering, Sistan and Baluchestan University, Zahedan, Iran \\ *Corresponding author E-mail: aidin.kahkeshan@gmail.com
}

Copyright $\odot 2014$ Mahmood Miri, Aidin Kahkeshan. This is an open access article distributed under the Creative Commons Attribution License, which permits unrestricted use, distribution, and reproduction in any medium, provided the original work is properly cited.

\begin{abstract}
Water elevated tanks are one of the most important tools in supplying water for cities. Due to their damages in previous earthquakes, and the necessity for keeping them in safe and usable condition after earthquakes is obvious. Thus, by making various modeling, their behavior under seismic loading is investigated. Moreover, the pros and cons of dampers are also evaluated. In this thesis, the proposed concrete water tank is modeled under three different earthquakes of Tabas, Northridge and Chichi. Moreover, the damper is located in three various positions. The results are illustrated for different fullness of tanks.
\end{abstract}

Keywords: Seismic Evaluation, Friction Damper, Earthquake.

\section{Introduction}

Civil engineering structures such as building, bridge and towers may be damaged under earthquake loads or even collapsed. Design of structures has been concern of the civil engineers for resistance against seismic damages. Despite many efforts and progresses in the applied codes, structures are always vulnerable to earthquake. The reason is that the designed structures with the common methods have limited resistance capacity. Major resistance of the structures is based on the negligible stiffness and damping of the materials applied in them for waste of energy. These structures are inactive because they are not adaptable based on the applied loads. To confront against earthquake load, resistance and ductility of structure increase but provision of the materials for such goals is expensive. Increase in dimensions of cross section applies more forces to them and as a result, it will have larger dimensions. There is no way for increasing damping of materials applied in the structure. These factors caused to start smart structures in 1970s. Generally, seismic control methods are divided into four subgroups in terms of performance type.

a) Seismic separation

b) Inactive control method

c) Semi-active control method

d) Active control method

In separation method, by increasing natural periods and predicting dampers following it, we reduce dynamic response of the structure. In the structures of tank, major part of mass is located in considerable distance of foundation. Analysis of these structures under lateral forces can be important and considerable particularly for security and keeping efficiency of these structures. Since period of these structures is usually high, it can be important to select suitable analytic method which can recognize performance of system at time of applying lateral forces. In this thesis, attempt is made to conduct necessary study and present results.

\section{Significance of subject}

Structure is a system which tolerates load and transfers it. Structure is designed such that fulfill this goal without irreparable damage during utilization. The structures are used as bridge, building, vessel etc. loads applied to the structure may be static, gravitational or dynamic loads such as earthquake. Structural elements include beam, column, and shell and braced frame which are regarded as structure. Behavior of structure and its components such as 
deformation under the applied loads or dynamic vibrations are called structural response. Design of structure is defined as determination of dimensions of cross sections and 3D configuration, type of material and its components, joints etc to fulfill design criteria. A structure should have safety (strength and stability) and exploitability (stiffness) against the applied loads. In design of the structure, different sciences such as mathematics, metallurgy and mechanics are used. Common approach in design of structures is that the structure has enough strength and stiffness against the applied loads and can be deformed. Such structures have low capacity for three reasons. First, these structures have low damping for waste of energy. In this case, there is no strategy for increasing material damping such as reinforced concrete and steel. Second, these structures have fixed capacity for strength and waste of energy. Therefore, they cannot act flexibility against the stimulations such as wind and earthquake. Third, these structures tolerate the applied loads generally with their stiffness. These limitations led researchers to find other strategies. The advanced studies along with use of modern materials (or smart materials) led to creation of structures which can change their inherent characteristics based on load. With these new systems and tools added to the structure, the structure act smartly because it can check its performance and adapt itself based on the applied loads. The smart structure can understand changes of load and store and process information to issue necessary command for protecting structure and protecting its consolidation. Application of these concepts in civil engineering is new for confronting against loads resulting from load and earthquake and many studies have been conducted in this field. Issue of strengthening water elevated tanks is necessary as one of the most important structures which provide drinkable water in cities considering their vulnerability in the past earthquakes and necessity of keeping their exploitability after occurrence of earthquake. Therefore, it is necessary to study advantages and disadvantages of using separators in its supports by performing necessary modeling while studying behavior of these structures during earthquake.

\section{Research questions and hypotheses}

The discussed questions in this research: Does use of frictional damper lead to reduction of target displacements? Does use of frictional damper lead to changes in base shear? The hypotheses applied in this research:

- Tank used in this research is concrete and cylindrical.

- Tank for different percents of fullness is analyzed.

- Dynamical analysis is done with three dimensions.

- SAP nonlinear software is used for modeling.

Dimensions of the desired tank are relatively small. For this reason, hydrodynamical effects of fluid are ignored inside the tank and interaction between behavior of fluid and structure is not considered.

\section{History of control systems in structure}

Application of the tools for controlling vibrations in the structure dates back 100 years ago. At that time, damping tools were used for controlling elevated water tank. Commercial use of these tools has started since 1970.

Use of control method was more frequent in automobiles and spatial structures but since 1950 later on, this system has been used for controlling structure against wind and earthquake stimulations [19]. Use of the concept "seismic response control" dates back 1950 by Miai and Kobori [1]. They concluded that accurate determination of specifications of earthquake is not possible, seismic response should be limited by the structure. The concept presented by Yao [2[is regarded as a starting point in seismic control research. Yao proposed a system of which behavior automatically changes when confronting with unpredictable changes and which gives suitable response against all loading conditions. In such structural system, wind and earthquake loads are tolerated by control force. Japan is regarded as a pioneer in practical use of the structure control. In 1985, full scale tests were performed in Japan and some studies were conducted on AMD systems since 1989 later on [3]. In USA and under supervision of National Foundation of Sciences, structural control projects started in 1992[4].

To progress application of structural control, IASC was established in 1992 and in the tenth conference of seismic engineering and after it; different international conferences were organized in this field. At present, laboratory researches are conducted on structural control against wind and earthquake loads and reduction of its effects and its summary is given in Table 1.1. Researchers achieved important results considering these researches and summary is given later.

- Modeling control system and development of algorithm: this focuses on improvement of control theory application and seismic response under uncertainties.

- Development of control tools and their authenticity: dampers and actuators which are applied for producing seismic response were developed widely and new control algorithms were proposed.

- Application of smart materials (such as smart Shape Memory Alloy) is being expanded and these materials are used for constructing dampers, sensors and structural elements.

- Applicability: these studies have promoted applicability of the control systems. Powerful control strategies, smart control techniques, production capacity of actuators and mixed control strategy have improved efficiency of the control systems and optimized their location, general safety of structure and its stability and maintenance. 
- $\quad$ Full scale tests: while use of inactive control system was widely common, full scale tests on the active control systems caused their progress.

- Development of design standards: seismic design rules and instructions are being studied for controlling structures. Major activities have been performed by FEMA for the isolated seismic structures and static and dynamic methods have been presented for the isolated structures in these manuals. ASCE, UBC and IBC have presented manuals for the isolated structures and application of dampers in their different versions.

1) Theory and Modeling

2) Analysis methods in earthquake resistant structures are divided into four groups including:

3) Linear static analysis (equivalent lateral force )

4) Linear dynamic analysis (spectral and time history)

5) Nonlinear static analysis (pushover)

6) Nonlinear dynamic analysis

Among the mentioned methods, static method for low-height structures with ordinary applications is applied like the conventional buildings and its use is not recommended for buildings with high importance. Other mentioned methods are used considering efficiency and time for analysis and cost in the entire structures. Since the applied force on a structure furring earthquake cannot be evaluated accurately with the equivalent lateral force, dynamic analysis for more accurate evaluation of the forces and behavior of structure is studied. In spectral linear dynamic method, maximum values of response for modes have been extracted from the design spectrum and have been summed with each other to yield total maximum response of the system. Types of summation are SRSS and CQC.

- In linear dynamic analysis of time history, the structure has been affected by an accelerometer. Its response is obtained in the structure as forces or displacements as history in different times. To solve and study structures in time history method, direct integration is used in small time intervals and by summing responses at any time, response history is obtained.

- In nonlinear dynamic analysis, behavior of materials and other specifications of the structure are nonlinearly modeled and analyzed. This method analyzes real behavior of the structure and mentions real responses and the reason is near real modeling of the structure and its components.

\subsection{Selective accelerometers}

Dynamic analysis of time history with earthquake accelerometer is one of the methods which have been proposed in most codes for studying seismic behavior of the structures and these accelerometers are generally divided into two classes:

a) The accelerometers which have been made based on spectrum of the code and numerical methods and are called artificial earthquake accelerometer. Specification of such accelerometers is that it is compatible with the code design and can indicate seismic characteristics of the desired zone. It can be easily used for seismic design.

b) The recorded accelerometers of the real earthquakes which usually include known and destructive earthquakes in different parts of the world. It can be said about these accelerometers that because seismic specifications of these earthquakes may be different from other zones and this difference can be also found in design of different zones and on the other hand, because these spectra are prepared based on the largest probable earthquake and design base earthquake, they should be scaled for using these accelerometers. In this research, three earthquakes accelerometers of Tabas, Northridge and ChiChi are used and general specifications of each one of them are given in Table 1. PGA is maximum earthquake acceleration, PGV is maximum earthquake speed, Duration is duration of the earthquake continuation and Time step is the interval of the data. In Figures 1 to 3, 20s of the most important part of the accelerometers is given.

Tabas earthquake was the earthquake with intensity of 7.8 Richter scales which ruined Tabas city and its adjacent villages at 7 P.M. on 16 September 1978. In this earthquake, about 15000 people died. Northridge earthquake heavily damaged structure of new low height buildings in California, America in 1994. Northridge earthquake occurred on 17 January 1994 at 12:30:55 P.M in UTC time in America. Depth of this earthquake was $11.4 \mathrm{~km}$ and its magnitude was announced 6.7 in Mw scale. Earthquake occurred in local time on Monday at 2 P.M. and its time zone was UTC08:00 (by changing summer hour). American Geology Organization has reported epicentre of this earthquake in western coordinates of northern $118^{\circ} 32^{\prime} 13^{\prime}$ ', western $537^{\circ} 12^{\prime} 47^{\prime}$ ', western $341^{\circ} 18^{\prime} 537^{\prime}$, , northern $34^{\circ} 213^{\prime \prime}$ and its depth to be $18 \mathrm{~km}$. Selective magnitude of this organization was 6.7 among the calculated magnitudes in Mw scale and it has announced earthquake with losses among four classes i.e. Intangible, tangible, harmful and with losses. More than 40000 buildings have been damaged in earthquake. Landside and liquefaction have occurred in this earthquake. The number of those killed in the earthquake has been approximately 33. The number of injured has been estimated 138 . The number of homeless people has been announced 20000. Chichi earthquake occurred on 20 September 1999 at 5:47:18 P.M in UTC time in Taiwan, Nanto County. Depth of this earthquake was $31.3 \mathrm{~km}$ and its magnitude was announced 7.6 in Mw scale. Earthquake occurred in local time on Tuesday at 1 P.M. and its time zone was UTC+08:00. American Geology Organization has reported epicenter of this earthquake in eastern coordinates of northern $120^{\circ} 58^{\prime} 55^{\prime}$ ', eastern $23120,982^{\circ} 46^{\prime} 19^{\prime}$ ', northern 23,772 and its depth to be $33 \mathrm{~km}$. Selective magnitude of this 
organization was 7.7 among the calculated magnitudes in Mw scale and it has announced earthquake with losses among four classes i.e. Intangible, tangible, harmful and with losses. Approximately 82000 buildings have been damaged in earthquake. Landside has occurred in this earthquake. The number of those killed in the earthquake has been approximately 2489. The number of injured has been estimated 11306 . The number of homeless people has been announced 600000 .

Table 1: Specifications of Selective Accelerometers

\begin{tabular}{lllll}
\hline Record & PGA $(\mathrm{g})$ & PGV $(\mathrm{cm} / \mathrm{s})$ & Duration $(\mathrm{s})$ & Time step(s) \\
\hline Tabas & 0.406 & 26.5 & 25 & 0.02 \\
Northridge & 0.358 & 27.5 & 40 & 0.02 \\
Chi Chi & 0.364 & 55.4 & 150 & 0.004 \\
\hline
\end{tabular}

\subsection{Calculating fluid dynamic force applied on the tank}

List of symbols:

$\mathrm{A}=$ earthquake regional coefficient

$\mathrm{I}=$ structure Importance coefficient

$\mathrm{C}=$ earthquake importance coefficient

$\mathrm{h}=$ total height of water

$\mathrm{W}=$ total weight of liquid

$\beta_{\text {eff }}=$ effective damping

$\mathrm{B}=$ Reflection coefficient

$\mathrm{R}=$ Structure performance coefficient

$\mathrm{P} 1=$ Equivalent static lateral force resulting from hard mass vibration

$\mathrm{D}=$ Diameter of water tank

$T_{e d} \quad=$ elastic period of system considering damping tools

$\xi_{0}=$ Damping ratio, $\beta_{0}=5 \%$

$\beta_{\text {eff }}=\xi_{\text {eq }}$

$T_{e}=$ Elastic period of system irrespective damping tools

Based on code 123 of Plan and Budget Organization for calculating fluid dynamic force and considering fluid dynamic force and hard mass in water tank which is equal to water mass in the tank which fluctuates, calculation of dynamical force is added to earthquake force as percent. For this purpose, $\mathrm{I}=1.4, \mathrm{R}=3$ and $\mathrm{A}=0.35$ have been considered. $\mathrm{P}_{1}$ has been defined as equivalent static lateral force resulting from vibration of hard mass. When the tank has $100 \%$ of filling, total height of water (h) is equal to $310 \mathrm{~cm}$. Diameter of water tank (D) is also equivalent to $500 \mathrm{~cm}$. based on the above diagram and hard mass curve, coefficient value is read equal to 0.57. As a result,

$W_{1}=0.57 \times W$

$\mathrm{W}$ is equal to total weight of liquid which is equal to 33.7 tons considering geometry of the tank, therefore, we have :

$W_{1}=0.57 \times 33.7=19.21$ ton

To determine effect of outcome P1 for determining pressure applied on the wall the above diagram has been used. On this basis, coefficient value is read equivalent to 0.38 . As a result, we have:

$\frac{h_{1}}{h}=0.38$

Considering total height of water which is equal to $310 \mathrm{~cm}$, value of $\mathrm{h}_{1}$ is calculated:

$h_{1}=0.38 \times 310=117.8 \mathrm{~cm}$

Based on code 123, value of force is equal to:

$P_{1}=\frac{A(2) I}{R} W_{1}$

$P_{1}=\frac{0.35 \times 2 \times 1.4}{3} \times 19.21=6.27$ ton

Results of calculating $\mathrm{P}_{1}$ are summarized in the following Table:

Table 2: Values of $\mathrm{P}_{1} 2$

\begin{tabular}{ll}
\hline Calculated force of $\mathrm{P}_{1}$ & Tank condition \\
\hline 0 & Empty tank \\
0.66 & Tank with $30 \%$ fullness \\
2.63 & Tank with $60 \%$ fullness \\
6.27 & Tank with $100 \%$ fullness \\
\hline
\end{tabular}

To distribute hydrodynamic pressure in height of cylindrical tank, constant $\mathrm{K}$ is calculated from the following Relation: $P_{1}=k\left[1.814 \gamma h^{2} R \times \tanh \left(\sqrt{3} \frac{R}{h}\right)\right]$ 
Table 3: Coefficients of $k$

\begin{tabular}{ll}
\hline$k$ & Tank condition \\
\hline 0 & Empty tank \\
0.168 & Tank with $30 \%$ fullness \\
0.17 & Tank with $60 \%$ fullness \\
0.162 & Tank with $100 \%$ fullness \\
\hline
\end{tabular}

With K, pressure distribution relation will be based on the following Relation:

$P_{0}=\sqrt{3} k \gamma h\left[\frac{y}{h}-0.5\left(\frac{y}{h}\right)^{2}\right] \tanh \left(\frac{R}{h}\right)$

In necessary calculations, a uniform pressure distribution should be included in height of wall. In these cases , average pressure of 0.9 is recommended as maximum pressure on the wall.

$P_{\text {ave }}=0.9 P_{0 \max }$

Table 4: Calculating Uniform Pressure Distribution

\begin{tabular}{lll}
\hline$P_{\text {ave }\left(\mathrm{kg} / \mathrm{m}^{2}\right)}$ & $P_{0 \max }$ & Tank condition \\
\hline 0 & 0 & Empty tank \\
593 & 659 & Tank with $30 \%$ fullness \\
2355 & 2617 & Tank with $60 \%$ fullness \\
5620 & 6245 & Tank with $100 \%$ fullness \\
\hline
\end{tabular}

\subsection{Steps required for the primary design of friction systems}

Steps required for rapid estimation of specifications of damper (slip load and brake cross section) have been introduced:

Step 1: we select equivalent damping level which frictional damper should provide. This parameter $\boldsymbol{\beta}_{\text {eff }}$ is usually between 15 and $20 \%$.

Step 2: using the following method, we calculate the related spectral reduction dependent on depreciation. Equivalent linearization steps which are practically used usually require use of spectral reduction factors to set the first response spectrum based on effective depreciation level $\left(\beta_{\text {eff }}\right)$. These factors are function of effective damping and are called damping coefficients ()$B\left(\beta_{\text {eff }}\right)$. They are used for setting spectral acceleration as follows:

$S_{a}\left(T, \beta_{\text {eff }}\right)=\frac{S_{a}(T, 5 \%)}{B}$

$B=\frac{A_{5 \%}}{A_{\beta_{\text {eff }}}}$

ATC 40 code suggests that Newmark and Hall's value for fixed acceleration and design spectrum medium speed zones is considered as follows:

$A_{a, \beta_{e f f}}=3.21-0.68 \ln \beta_{\text {eff }}($ in $\%) \Rightarrow B_{s}=\frac{2.12}{A_{a, \beta_{e f f}}}$

$A_{v, \beta_{\text {eff }}}=2.31-0.41 \ln \beta_{\text {eff }}($ in $\%) \Rightarrow B_{1}=\frac{1.65}{A_{v, \beta_{\text {eff }}}}$

NEHRP 2000code suggests that Newmark and Hall's value for fixed speed in design spectrum is considered as follows:

$A_{v, \beta_{\text {eff }}}=2.31-0.41 \ln \beta_{\text {eff }}(\mathrm{in} \%) \Rightarrow B_{1}=\frac{1.65}{A_{v, \beta} \text { eff }}$

FEMA 356 code suggests values as Table. This code uses two factors, one for response spectrum fixed acceleration area $\left(B_{S}\right)$ and another one for spectrum fixed speed area $\left(B_{1}\right)$. When damping ratio value exceeds $50 \%$, effect of damping on reduction of displacements is ignored. FEMA 440 suggests the following value:

$B=\frac{4}{5.60-\ln \beta_{\text {eff }}(\text { in } \%)}$

Step 3: effect of period transfer should be considered. Equivalent linearization steps which are used practically require use of effect of period transfer with reduction of spectral reduction for setting equivalent linear system. As a result, we have:

$\frac{S_{a}\left(T_{e d}, \xi_{e q}\right)}{S_{a}\left(T_{e}, \xi_{0}\right)}=\frac{S_{a}\left(T_{e d}, \xi_{e q}\right)}{S_{a}\left(T_{e d}, \xi_{0}\right)} \times \frac{S_{a}\left(T_{e d}, \xi_{0}\right)}{S_{a}\left(T_{e}, \xi_{0}\right)}$

In step 2, ratio of $S_{a}\left(T, \xi_{e q}\right) / S_{a}\left(T, \xi_{0}\right)$ has been determined for all ranges of period. As a result, the first term on the right hand of the Equation is determined. The second term can be interpreted as follows using basic idea in Newmark and Hall's quasi-static design spectrum:

$\frac{S_{a}\left(T_{e d}, \xi_{0}\right)}{S_{a}\left(T_{e}, \xi_{0}\right)}=\left(\frac{T_{e d}}{T_{e}}\right)^{P}$

Considering the above Equation, it is concluded that value $\mathrm{P}$ index is added with increasing period of system. Considering that the equivalent period $\left(T_{e d}\right)$ is always larger than the primary period $\left(T_{e}\right)$, the shorter the period, the larger the spectral acceleration. 
$V_{y}=\frac{W \times S_{a}\left(T_{e}, 5 \%\right)}{R_{\mu}}$

A structure without damper is defined for the following equivalent lateral force:

For the structure similar to the previous state and with equivalent damping system, real final resistance will be equal to:

$V_{y d}=\frac{W \times S_{a}\left(T_{e d}, \xi_{e q}\right)}{R_{\mu}}$

$\frac{S_{a}\left(T_{e d}, \xi_{e q}\right)}{S_{a}\left(T_{e}, \xi_{0}\right)}=\frac{V_{y d}}{V_{y}}=\frac{1}{B} \times\left(\frac{T_{e d}}{T_{e}}\right)^{P}$

Considering the second and third steps, it is concluded that:

Elastic period of the damped system $\left(T_{e d}\right)$ is related to the undamped system (5\% of damping) based on the following Relation:

$\frac{T_{e d}}{T_{e}} \approx\left(\frac{I_{e}}{I_{d}}\right)^{\frac{1}{2}} \approx\left(\frac{h_{e}}{h_{d}}\right)^{\frac{3}{2}} \approx\left(\frac{z_{e}}{z_{d}}\right)^{\eta} \approx\left(\frac{V_{y}}{V_{y d}}\right)^{\eta}$

In the above Relation, $I_{e}$ and $I_{d}$ are inertia moments of the beams of undamped and damped structures. $\mathrm{H}$ and $\mathrm{z}$ are height of the cross section and plastic modulus of cross section for both structures. $\eta$ Can be between 0.45 and 0.65 for section, 0.75 for rectangular section and 0.66 for circular section. Value of 0.5 can be considered suitable. As a result, we will have:

$\frac{V_{y d}}{V_{y}}=\frac{1}{B} \times\left(\frac{V_{y}}{V_{y d}}\right)^{\frac{P}{2}}$

For fixed acceleration area with $\mathrm{p}=0$, we have:

$\frac{S_{a}\left(T_{e d}, \xi_{e q}\right)}{S_{a}\left(T_{e}, \xi_{0}\right)}=\frac{V_{y d}}{V_{y}}=\frac{1}{B}$

For fixed speed area with $\mathrm{p}=-1$, we have:

$\frac{S_{a}\left(T_{e d}, \xi_{e q}\right)}{S_{a}\left(T_{e}, \xi_{0}\right)}=\frac{V_{y d}}{V_{y}}=\frac{1}{B^{2}}$

$\frac{S_{a}\left(T_{e d}, \xi_{e q}\right)}{S_{a}\left(T_{e}, \xi_{0}\right)}=\frac{V_{y d}}{V_{y}}=\left\{\begin{array}{cc}\frac{1}{B} & T_{e}, T_{e d}<T_{s} \\ \frac{1}{B^{2}} & T_{e}, T_{e d}>T_{s}\end{array}\right\}$

As a result, we can conclude that:

It should be noted that for the equivalent damping level of 15 to $20 \%$, spectral reduction is $66 \%$ to $72 \%$ in fixed acceleration area and 42 to $52 \%$ in fixed speed area. As a result, approximately, base shear value is reduced from $0.72 V_{b}$ to $0.65 V_{b}$ for fixed acceleration area and reduced from $0.52 V_{b}$ to $0.42 V_{b}$ in fixed speed area by selecting suitable dampers. It should be noted that minimum permissible base shear for design of the system resistant against seismic loads is equal to:

$V_{\text {min }}=\frac{V}{B} \geq 0.75 \mathrm{~V}$

Limit value of $0.75 \mathrm{~V}$ usually indicates minimum construction strength with $15 \%$ of damping. Based on studies, this level of base shear reduction is very conservative. When design of system against seismic loads is based on plastic analysis, the required shear resistance in the construction base is equal to:

$V_{y}=V_{\min } \Omega_{0} \frac{C_{d}}{R}$

Step 4: we first calculate factors of reducing spectrum relating to steps 2 and 3. Then, equivalent static loads applied on the structure are determined. These loads are applied on the structure with damper (stiffness of the damped system is included in this Section).

\subsection{Slip load of friction damper}

Friction dampers are designed such that they don't slip against wind load. During a large earthquake, these dampers slip before yield of the structural elements. In general case, lower limit is about $130 \%$ of the shear caused by wind and upper limit is about $75 \%$ of the shear which leads to yield of the elements. Based on Diagram of Figure 23-3 which has been drawn as response against slip load, in case slip load is very low or high, the obtained response value will be high. Many analytical studies show that slip load of friction damper is the main variable in selection of suitable damper for optimizing responses of the structure because the most optimal slip load leads to the minimum responses. Selection of slip load should ensure that the structure retunes to its primary position after earthquake. A study also showed that range of variations up to $25 \%$ of the optimal load has no serious effect on the responses. 


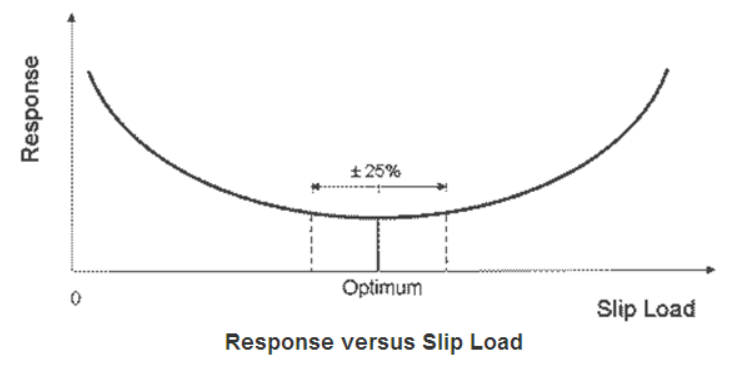

Fig. 1: Response Slip Load Curve

NEHRP code suggests that friction damper for displacements resulting from $130 \%$ of the Maximum considered earthquake should be designed. All braces and joints should be designed for $130 \%$ of the slip load of the damper. Variations in slip load should not be lower or higher than $15 \%$.

\subsection{Modeling friction damper in sap software}

Modeling of the friction damper in software SAP 2000 is studied. In link/support type section, type of damper is selected. Considering the review of literature on subject of the thesis, it has been recommended that plastic (wen) element be used for modeling friction damper. The reason is that hysteresis curve of friction damper is similar to an ideal elastoplastic material and has a fully rectangular form.

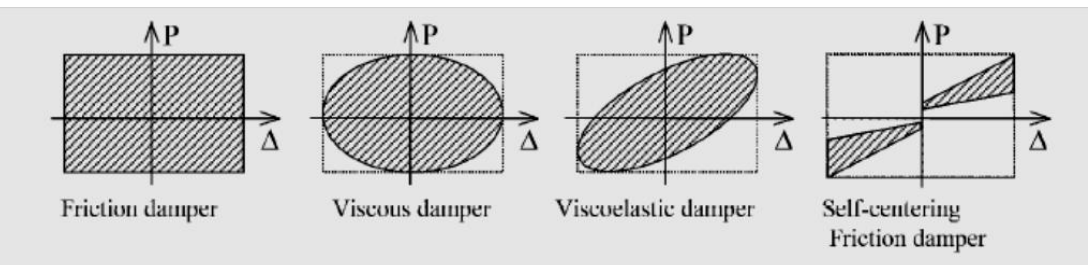

Fig. 2: Comparing Hysteresis Curve in Different Dampers

Table 5: input parameters in software (required parameters for modeling)

\begin{tabular}{ll}
\hline Software parameter & Numerical value \\
\hline Mass & $10 \frac{\mathrm{KN} \cdot \mathrm{s}^{2}}{\mathrm{~m}}$ \\
Effective stiffness & $17858 \frac{\mathrm{KN}}{\mathrm{m}}$ \\
Effective damping & $15 \%$ \\
stiffness & $17858000 \frac{\mathrm{KN}}{\mathrm{m}}$ \\
Yield strength & $22680 \mathrm{KN}$ \\
Yield exponent & 1 \\
Post yield strength ratio & 0.1 \\
\hline
\end{tabular}

By including the required parameters and defining conditions of the friction damper in menu draw and option one joint link in supports of the structure, this damper is drawn.

\section{Results of modeling}

To show the results more clearly, friction stimulations have been settled in three positions of foundation level, middle level of columns and upper level from results of the first $20 \mathrm{~s}$. the results for fullness state of 100\%, 60\% and 30\% and empty tank have been shown. The above results have been recorded for three earthquake records i.e. Chi-Chi , Northridge and Tabas .

\subsection{Results of analysis without damper}

In this Section, we studied results of analyzing the models. Displacement of upper level of tank in fullness state 


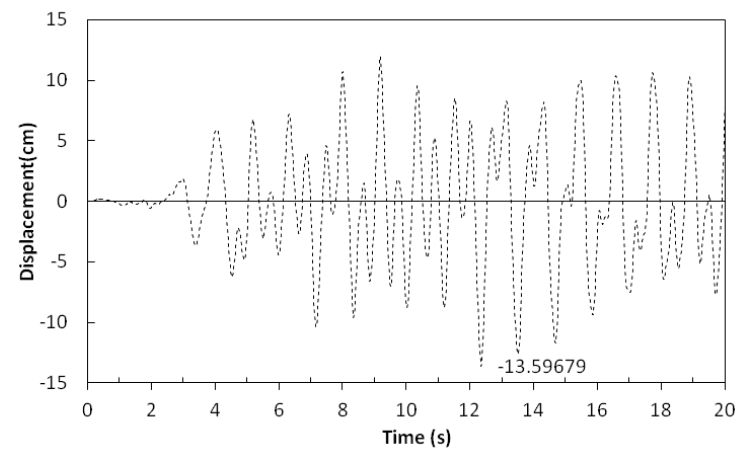

Diagram 2: Displacement of Upper Level of Tank in Fullness State Of 100\% under Tabas Earthquake

Considering the above diagram, Displacement of upper level of tank in fullness state of 100\% under Tabas Earthquake is $13.6 \mathrm{~cm}$ in case no damper is used.

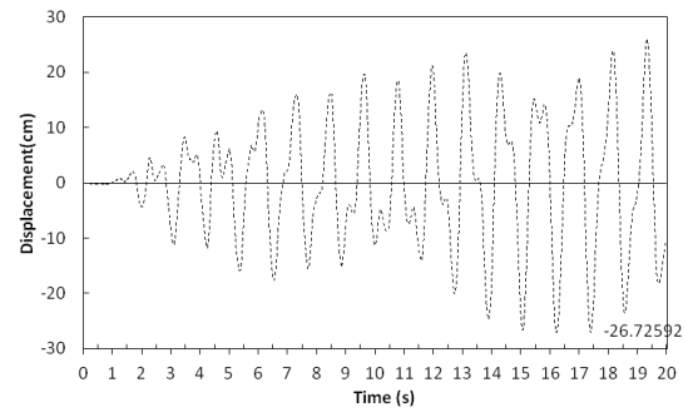

Diagram 3: Displacement of Upper Level of Tank in Fullness State of 100\% under Northridge Earthquake

Considering the above diagram, Displacement of upper level of tank in fullness state of $100 \%$ under Northridge Earthquake is $26.7 \mathrm{~cm}$ in case no damper is used.

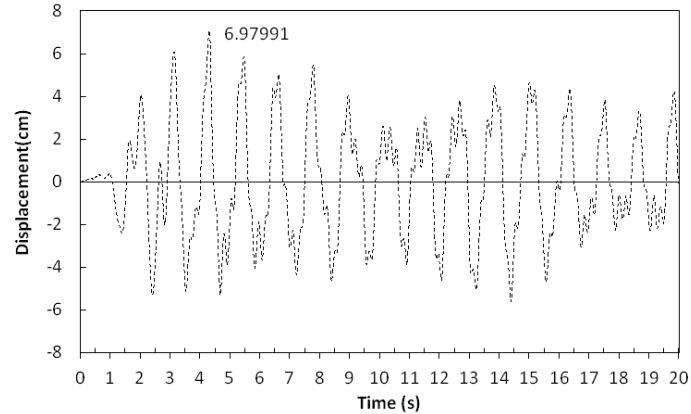

Diagram 4: Displacement of Upper Level of Tank in Fullness State of 100\% under Chi-Chi Earthquake

Considering the above diagram, Displacement of upper level of tank in fullness state of $100 \%$ under Chi-Chi Earthquake is $6.9 \mathrm{~cm}$ in case no damper is used.

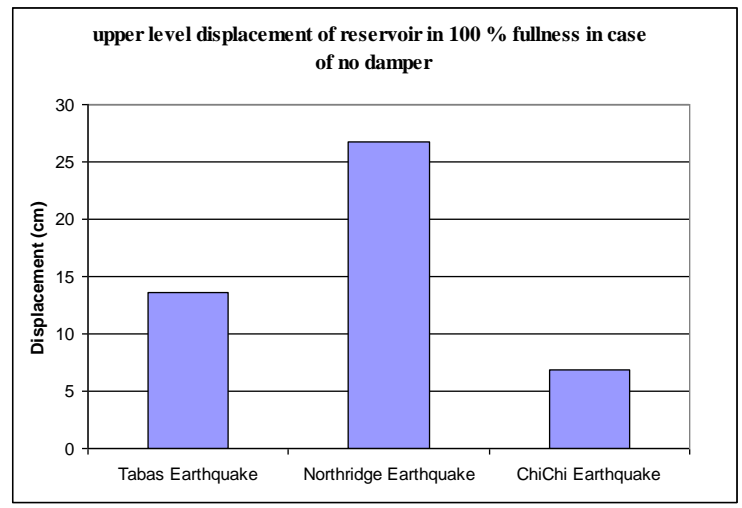

Diagram 5: Comparing Displacement of Upper Level of Tank in Fullness State Of 100\% under the Studied Earthquakes 


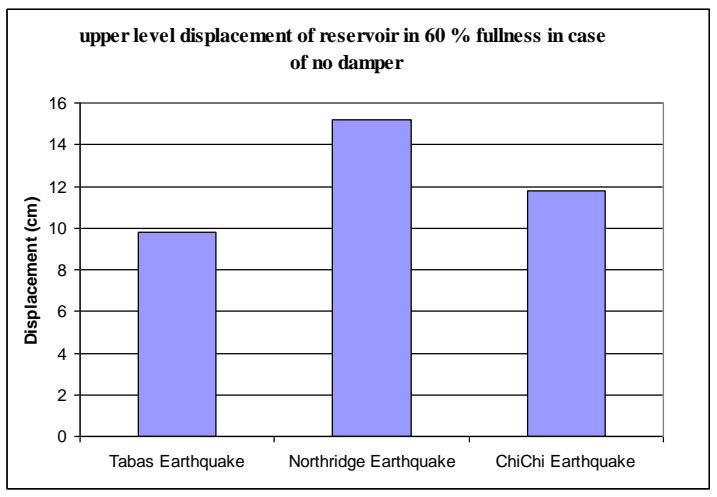

Diagram 6: Comparing Displacement of Upper Level of Tank in Fullness State Of 60\% under the Studied Earthquakes

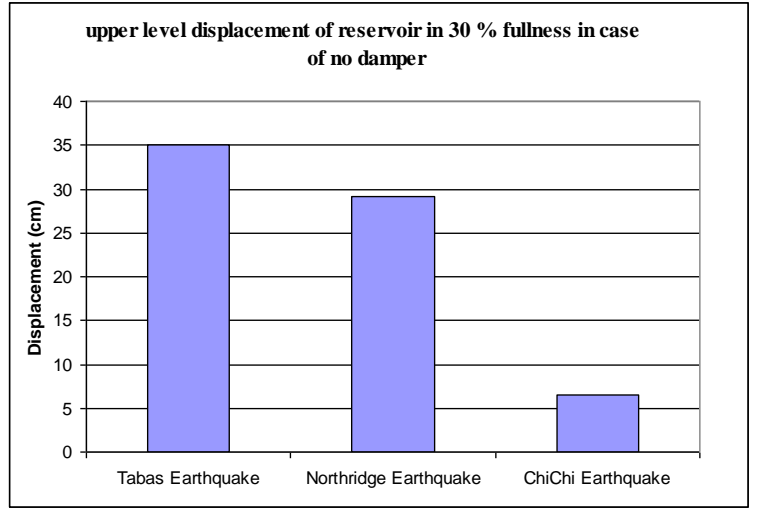

Diagram 7: Comparing Displacement of Upper Level of Tank in Fullness State Of 30\% under the Studied Earthquakes

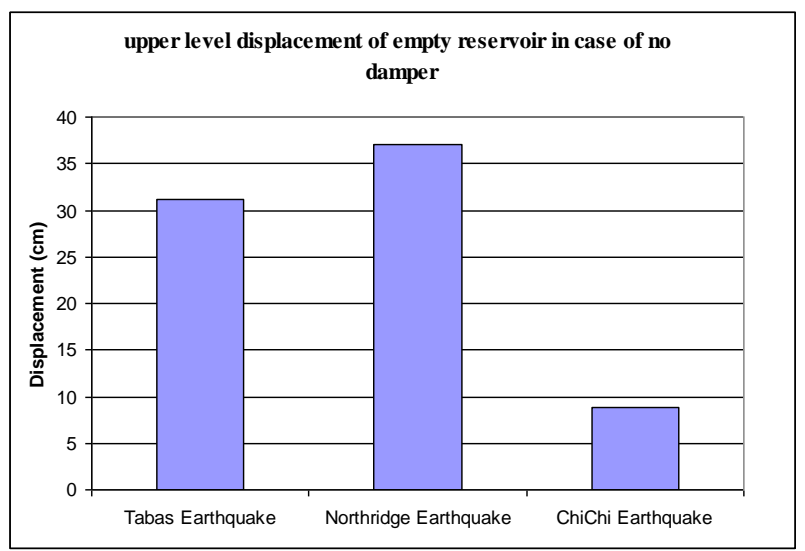

Diagram 8: Comparing Displacement of Upper Level of Tank in Empty Tank under the Studied Earthquakes

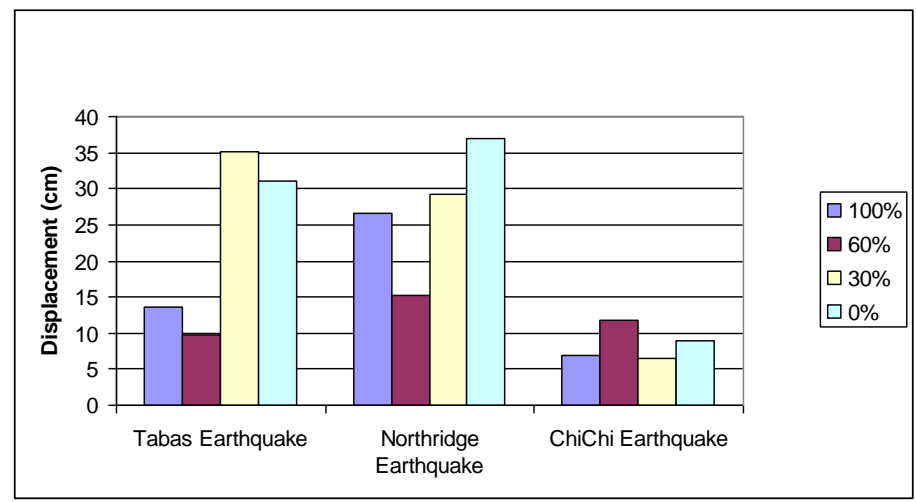

Diagram 9: Comparing Displacement of Upper Level of Tank in Empty Tank under the Studied Earthquakes

The above diagram shows displacement of upper level of tank in filled tank for all three earthquake records i.e. Chi-Chi Northridge and Tabas in case damper is not available. 


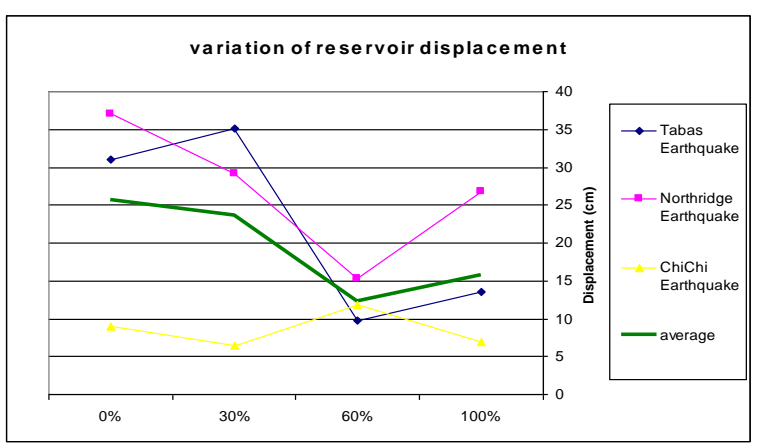

Diagram 10: Comparing Displacement of Upper Level of Tank in Empty Tank under the Studied Earthquakes

Based on the above diagram, it is observed that when damper is not used, general trend of displacements in level of water tank is such that displacement is reduced with increasing fullness of the tank. Of course, this trend is approximate and it is observed that the lowest displacement occurs for fullness of $60 \%$ in case damper is not used. Displacement fluctuates between $25.7 \mathrm{~cm}$ and $15.7 \mathrm{~cm}$ from empty state to fullness state of $100 \%$, therefore, fullness of the tank reduces displacement by $40 \%$.

\subsection{Studying results of analysis with damper}

Displacement of upper level of tank in fullness state

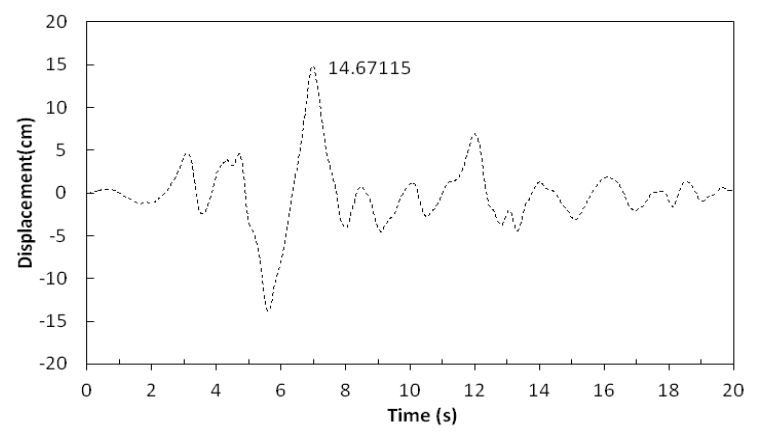

Diagram 11: Displacement of Upper Level of Tank in Fullness State Of 100\% in Case There Is Damper in Foundation Level under Tabas Earthquake

Considering the above diagram, Displacement of upper level of tank in fullness state of $100 \%$ under Tabas Earthquake is $14.6 \mathrm{~cm}$ in case there is damper in foundation level.

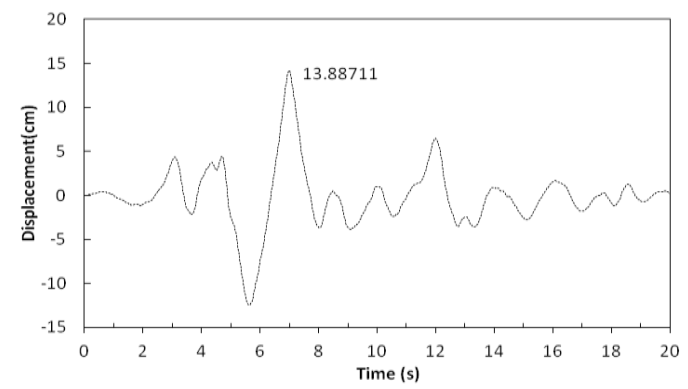

Diagram 12: Displacement of Upper Level of Tank in Fullness State Of 100\% in Case There Is Damper in Middle Level under Tabas Earthquake

Considering the above diagram, Displacement of upper level of tank in fullness state of $100 \%$ under Tabas Earthquake is $13.86 \mathrm{~cm}$ in case there is damper in middle level. 


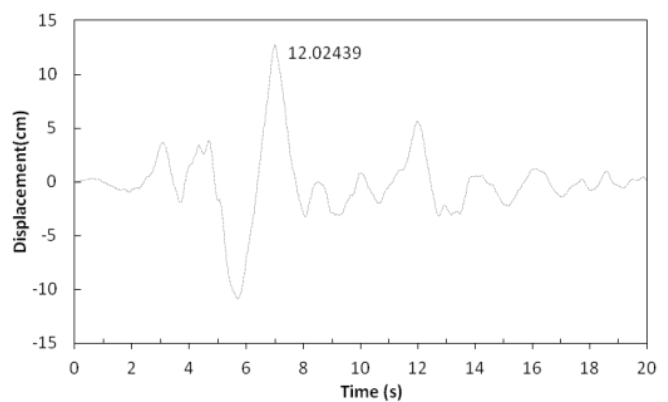

Diagram 13: Displacement of Upper Level of Tank in Fullness State Of 100\% in Case There Is Damper in Upper Level under Tabas Earthquake

Considering the above diagram, Displacement of upper level of tank in fullness state of $100 \%$ under Tabas Earthquake is $12.02 \mathrm{~cm}$ in case there is damper in upper level.

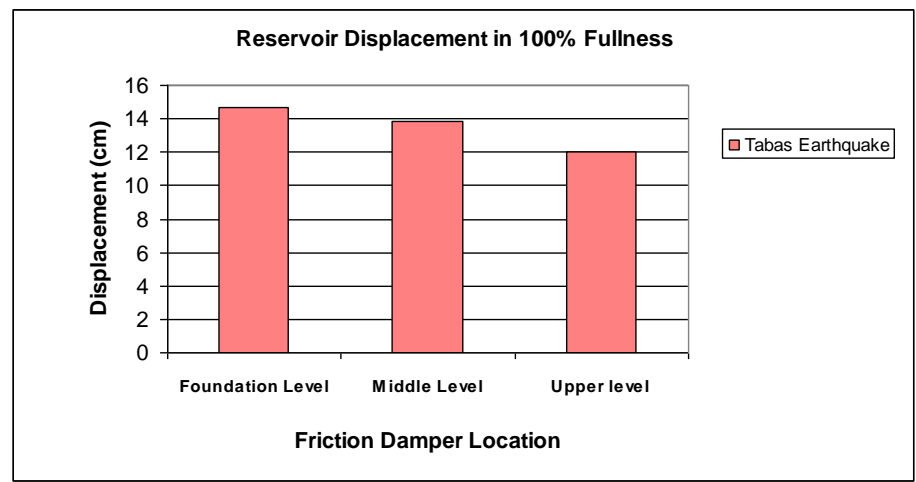

Diagram 13: Displacement of Upper Level of Tank in Fullness State of 100\% for Different Positions of Damper under Tabas Earthquake

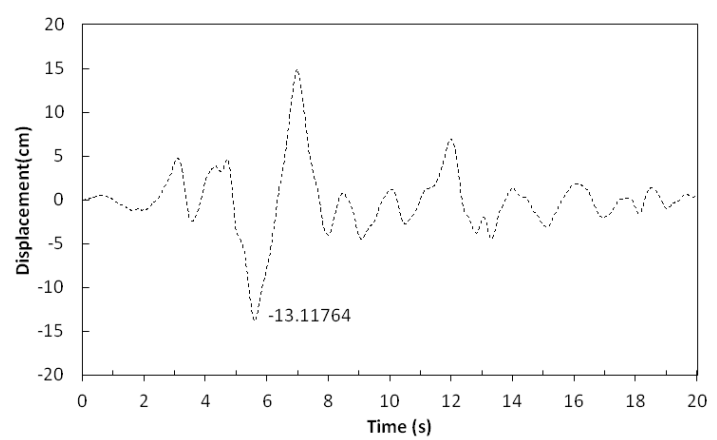

Diagram 15: Displacement of Upper Level of Tank in Fullness State of 100\% in Case There Is Damper In Foundation Level under Northridge Earthquake

Considering the above diagram, Displacement of upper level of tank in fullness state of $100 \%$ under Northridge Earthquake is $13.1 \mathrm{~cm}$ in case there is damper in foundation level.

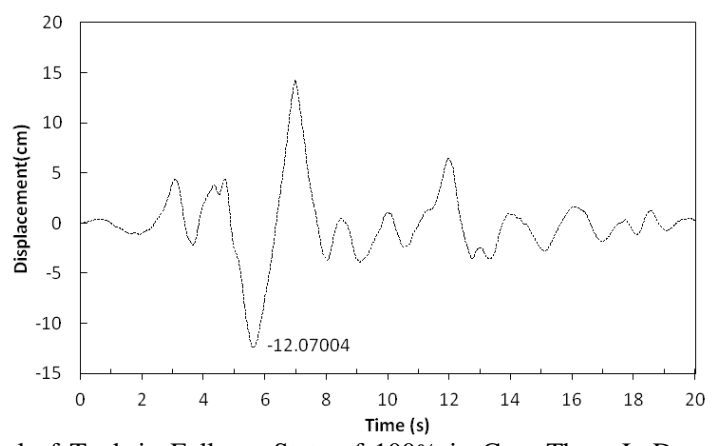

Diagram 16: Displacement of Upper Level of Tank in Fullness State of $100 \%$ in Case There Is Damper in Foundation Level under Northridge Earthquake

Considering the above diagram, Displacement of upper level of tank in fullness state of $100 \%$ under Northridge Earthquake is $12.0 \mathrm{~cm}$ in case there is damper in foundation level. 


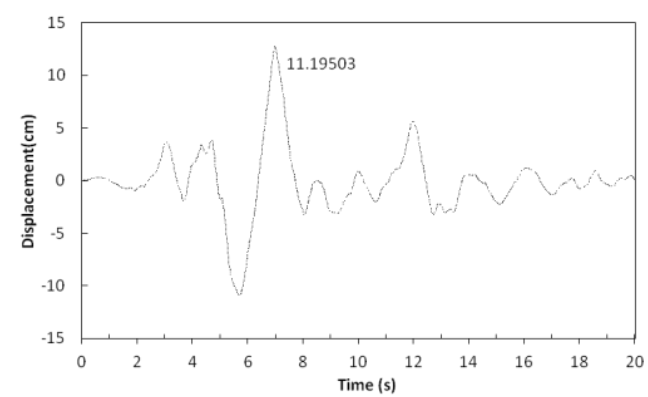

Diagram 17: Displacement of Upper Level of Tank in Fullness State of 100\% in Case There Is Damper in Upper Level under Northridge Earthquake

Considering the above diagram, Displacement of upper level of tank in fullness state of $100 \%$ under Northridge Earthquake is $11.1 \mathrm{~cm}$ in case there is damper in upper level.

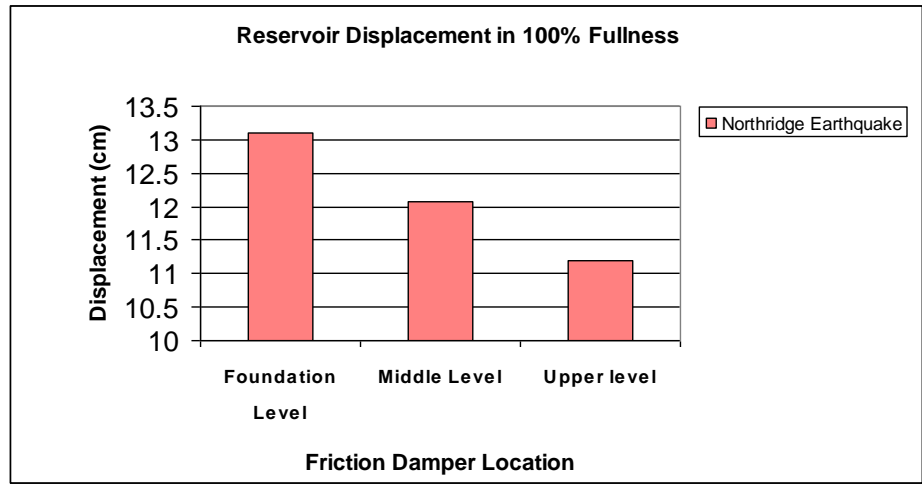

Diagram 18: Displacement of Upper Level of Tank in Fullness state of 100\% For Different Positions of Damper under Northridge Earthquake

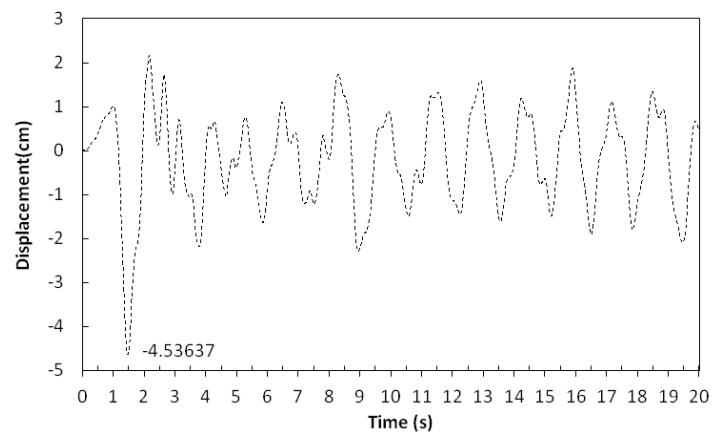

Diagram 19: Displacement of Upper Level of Tank in Fullness State Of $100 \%$ in Case There Is Damper in Foundation Level under Chi-Chi Earthquake

Considering the above diagram, Displacement of upper level of tank in fullness state of $100 \%$ under Chi-Chi Earthquake is $4.5 \mathrm{~cm}$ in case there is damper in upper level .

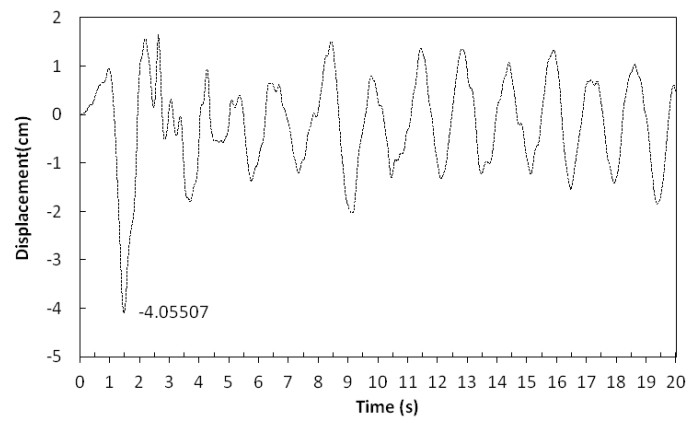

Diagram 20: Displacement of Upper Level of Tank in Fullness State of $100 \%$ in Case there is Damper in Middle Level under Chi-Chi Earthquake

Considering the above diagram, Displacement of middle level of tank in fullness state of $100 \%$ under Chi-Chi Earthquake is $4.0 \mathrm{~cm}$ in case there is damper in foundation level. 


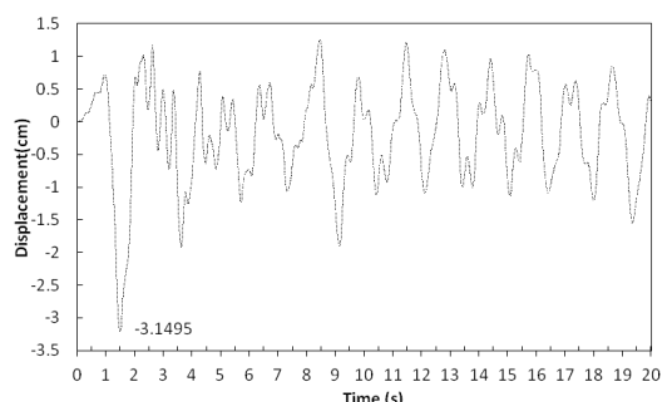

Diagram 21: Displacement of Upper Level of Tank in Fullness State Of $100 \%$ in Case there is Damper in Upper Level under Chi-Chi Earthquake

Considering the above diagram, Displacement of upper level of tank in fullness state of $100 \%$ under Chi-Chi Earthquake is $3.1 \mathrm{~cm}$ in case there is damper in upper level.

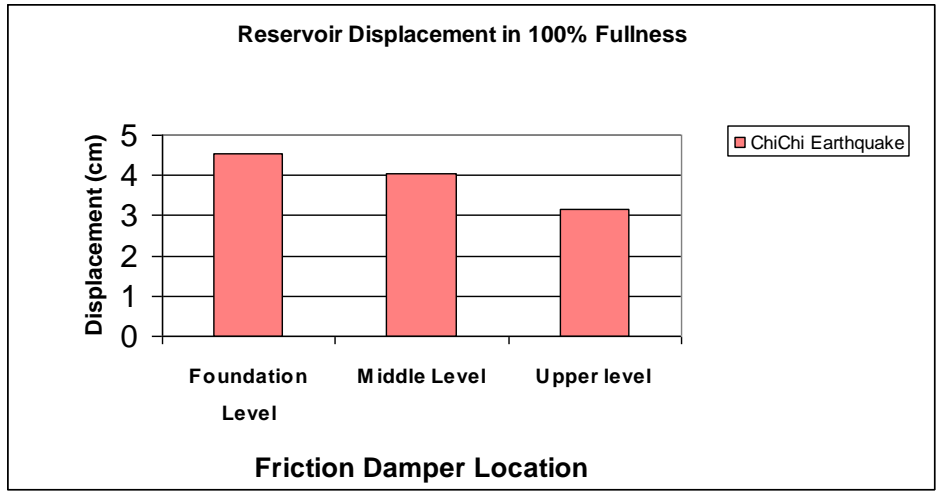

Diagram 22: Displacement of Upper Level of Tank in Fullness state of $100 \%$ For Different Positions of Damper under Chi-Chi Earthquake

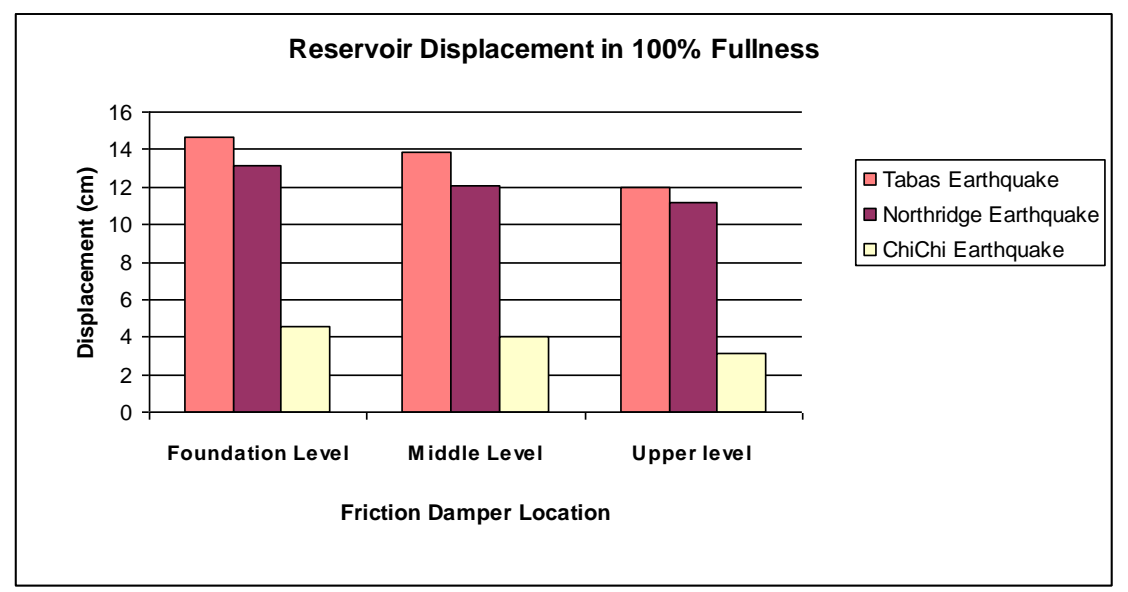

Diagram 23: Displacement of Upper Level of Tank in Fullness State of 100\% for Different Positions of Damper

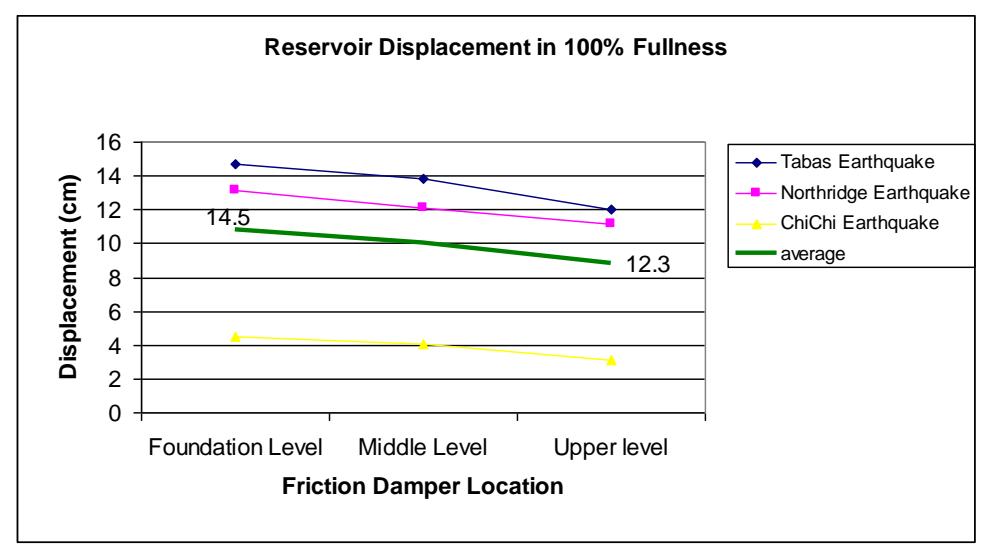

Diagram 24: Displacement of Upper Level of Tank in Fullness State of 100\% for Different Positions of Damper 
Considering the above diagram, general trend of displacement is descending and this value has been reduced from 10.7 $\mathrm{cm}$ for installation of damper in foundation level to $8.7 \mathrm{~cm}$ for installation of damper in upper level. This reduction is equivalent to $18.7 \%$.

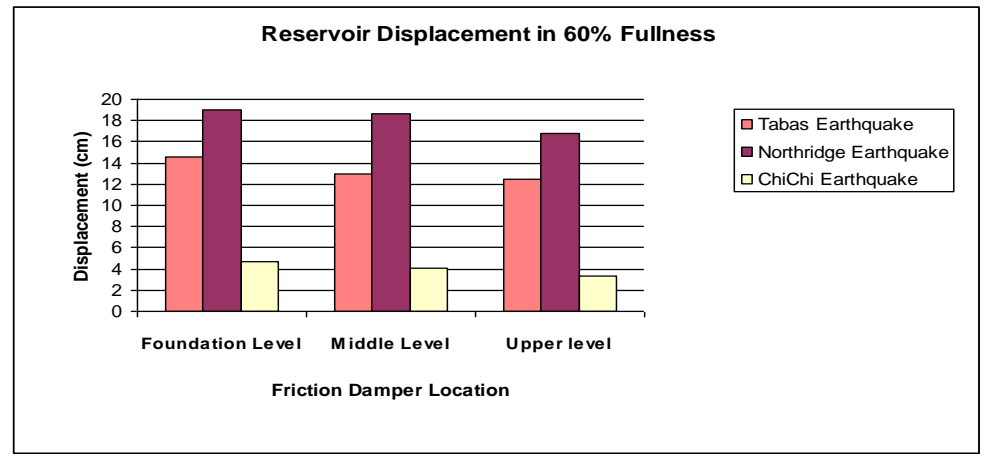

Diagram 25: Displacement of Upper Level of Tank in Fullness State Of 60\% for Different Positions of Damper

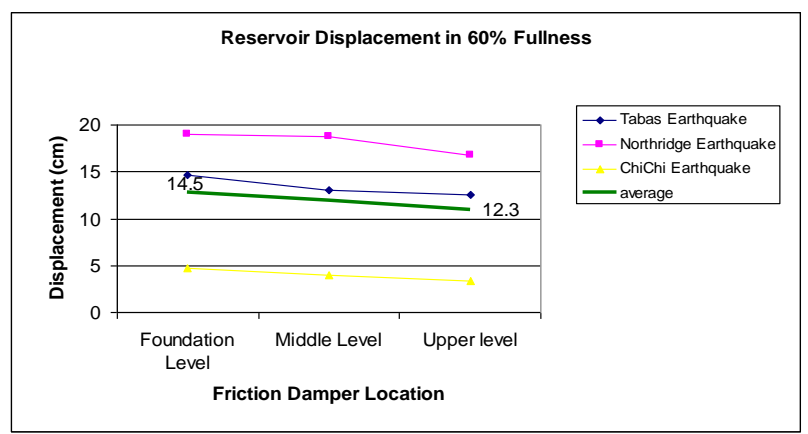

Diagram 26: Displacement of Upper Level of Tank in Fullness State Of 60\% for Different Positions of Damper

Considering the above diagram, general trend of displacement is descending and this value has been reduced from 12.7 $\mathrm{cm}$ for installation of damper in foundation level to $10.8 \mathrm{~cm}$ for installation of damper in upper level. This reduction is equivalent to $15 \%$.

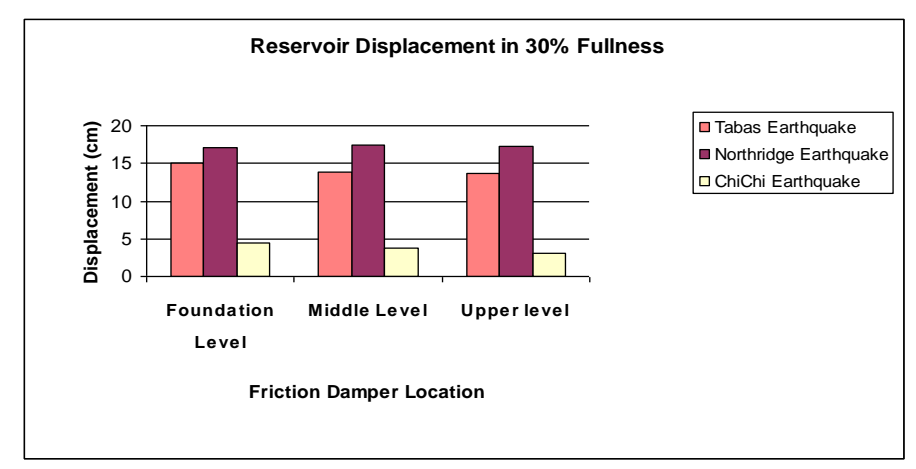

Diagram 27: Displacement of Upper Level of Tank in Fullness State Of 30\% for Different Positions of Damper

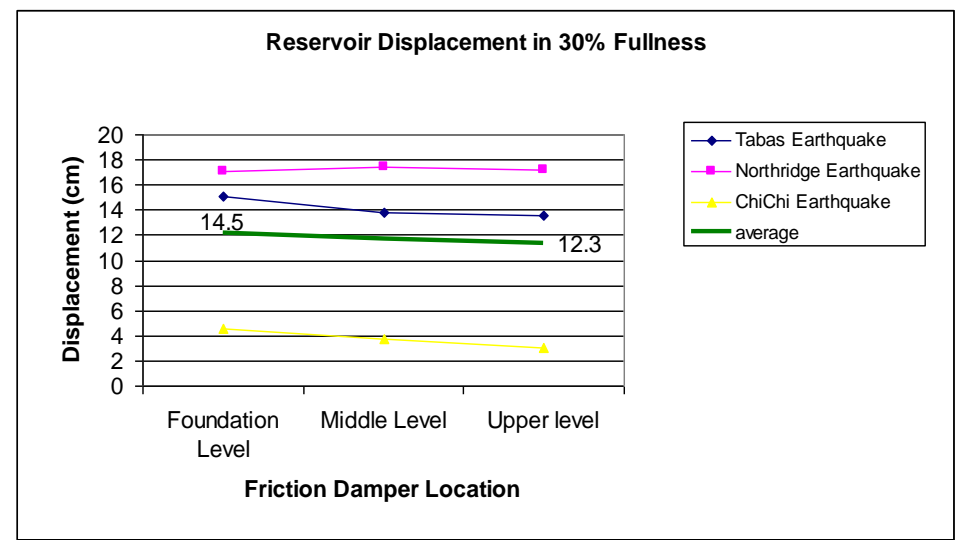

Diagram 28: Displacement of Upper Level of Tank in Fullness State Of 30\% for Different Positions of Damper 
Considering the above diagram, general trend of displacement is descending and this value has been reduced from 12.1 $\mathrm{cm}$ for installation of damper in foundation level to $11.2 \mathrm{~cm}$ for installation of damper in upper level. This reduction is equivalent to $7 \%$.

Displacement of empty upper level for empty tank

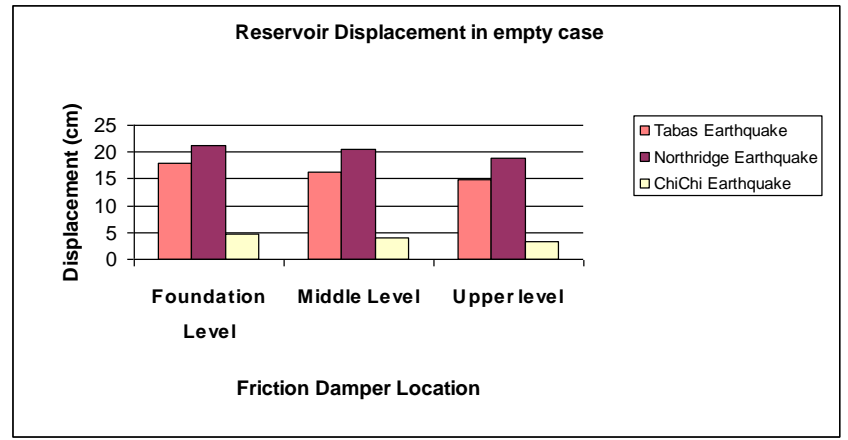

Diagram 29: Displacement of Upper Level of Empty Tank for Different Positions of Damper

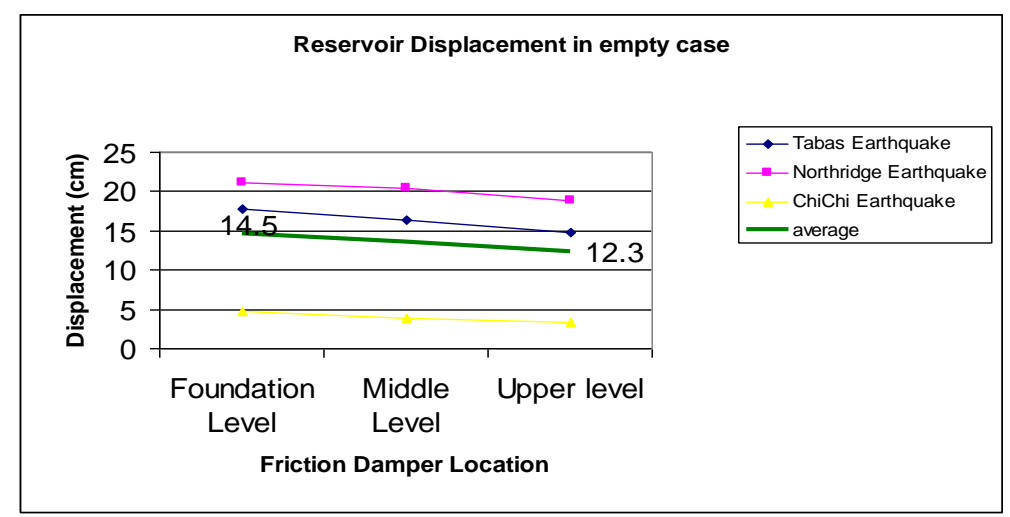

Diagram 30: Displacement of Upper Level of Empty Tank for Different Positions of Damper

Considering the above diagram, general trend of displacement is descending and this value has been reduced from 14.5 $\mathrm{cm}$ for installation of damper in foundation level to $12.3 \mathrm{~cm}$ for installation of damper in upper level. This reduction is equivalent to $15 \%$.

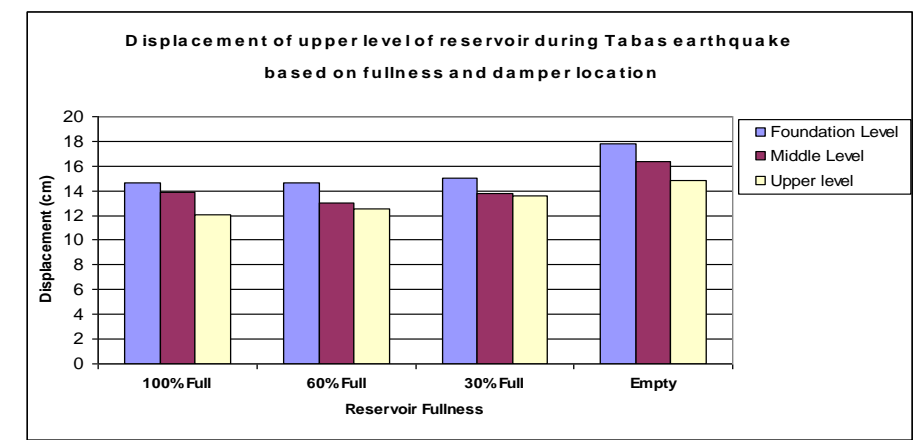

Diagram 31: Displacement of Upper Level of Tank Based on Position of Damper for Different States in Tabas Earthquake

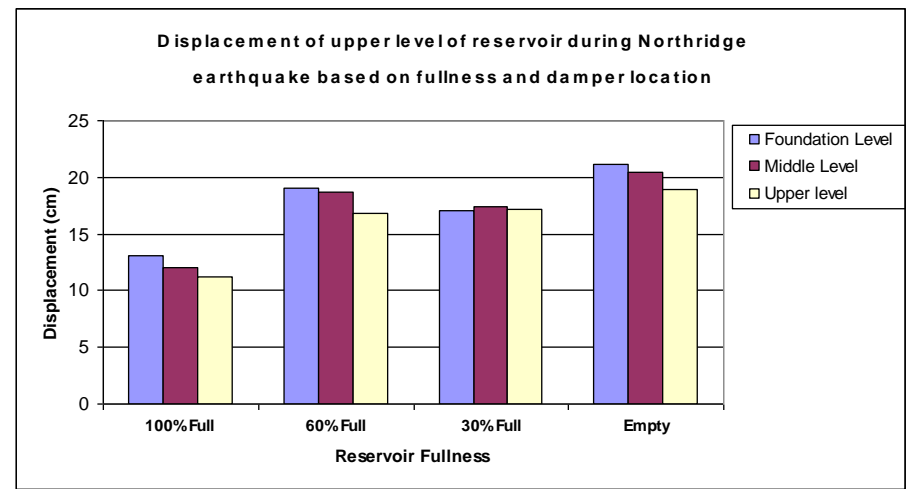

Diagram 32: Displacement of Upper Level of Tank Based on Position of Damper for Different States in Northridge Earthquake 


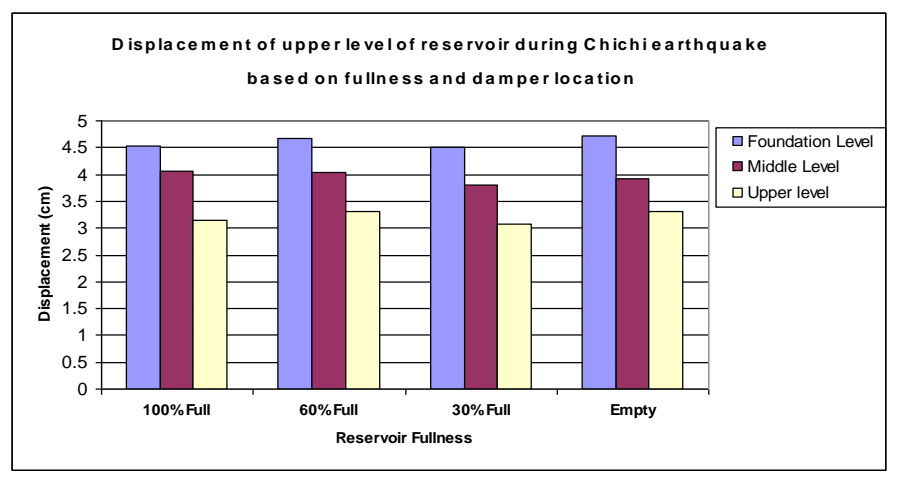

Diagram 33: Displacement of Upper Level of Tank Based on Position of Damper for Different States in Chi-Chi Earthquake

Considering the drawn diagrams, it is found that installation of damper in upper level reduces displacements in all occurring earthquakes and shows better performance. This reduction in displacements is between 8 and $19 \%$. In case of using damper, the highest displacements have been recorded for empty tank. The above results show suitable position of damper in upper level. Therefore, results of base shear have been studied and compared only for this state.

4.3. Comparing base shear in different states of tank

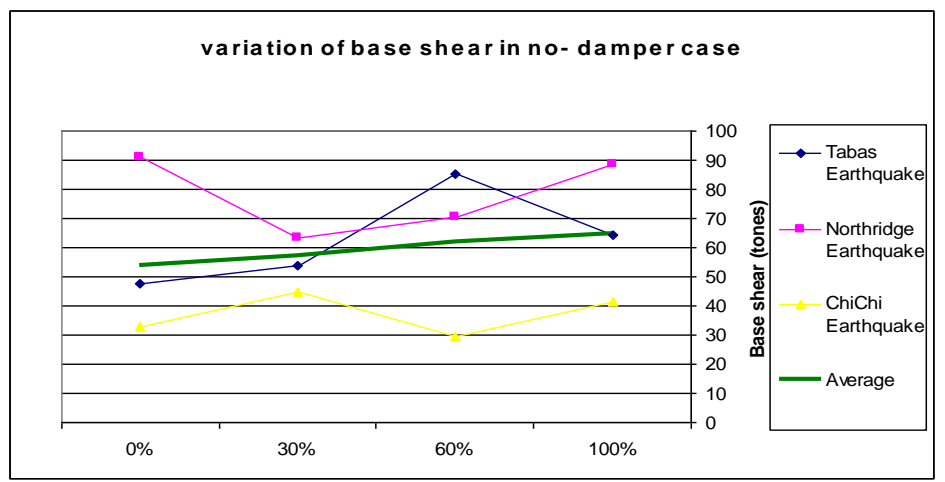

Diagram 34: Variations of Base Shear in Different States of Tank without Damper

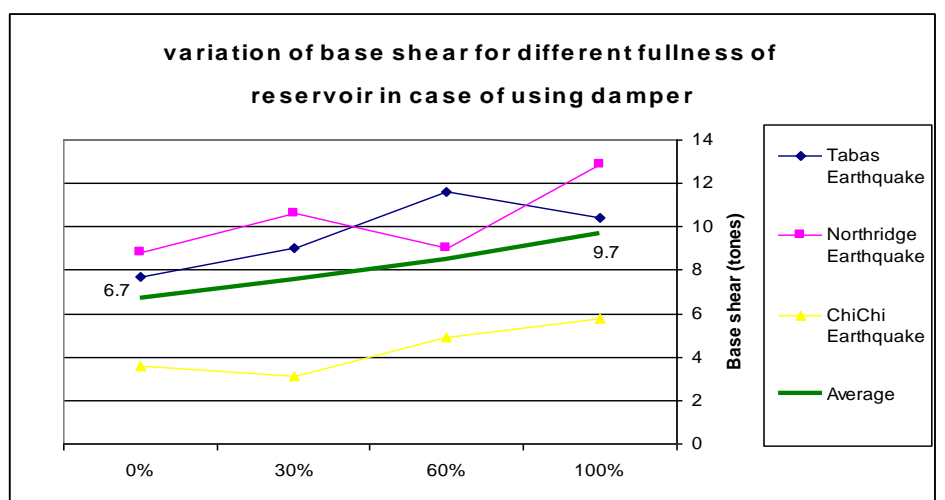

Diagram 35: Variations of Base Shear in Different States of Tank with Damper

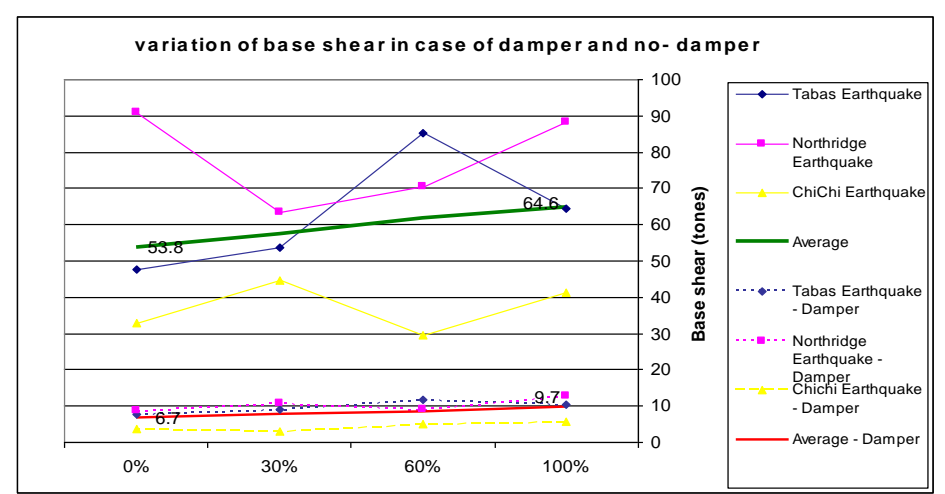

Diagram 36: Variations of Base Shear in Different States of Tank With or Without Damper 
Considering the Figure, it is found that mean trend of variations in base shear is descending with decreasing fullness of tank. In case of using damper in the upper level of elevated water tank, base shear is reduced from 9.7 tons for fully filled tank to 6.7 tons for empty tank. This reduction rate is equivalent to $31 \%$. In case the damper is not used, base shear is reduced from 64.6 tons to 53.8 tons. . This reduction rate is equivalent to $17 \%$. As a result, use of friction damper reduces mean of $14 \%$ in base shear of the structure.

\section{Conclusion}

Water elevated tanks are one of the most important tools in supplying water to cities. Due to their damages in previous earthquakes, and the necessity for keeping them in safe and usable condition after earthquakes is obvious. Thus, by making various modeling's, their behavior under seismic loading is investigated. Moreover, the pros and cons of dampers are also evaluated. In this thesis, the proposed concrete water tank is modeled under three different earthquakes of Tabas, Northridge and Chichi. Moreover, the damper is located in three various positions. The results are illustrated for different fullness of tanks.

1) Considering the results, it is found that mean trend of variations in base shear is descending with decreasing fullness of tank. In case of using damper in the upper level of elevated water tank, base shear is reduced from 9.7 tons for fully filled tank to 6.7 tons for empty tank. This reduction rate is equivalent to $31 \%$. In case the damper is not used, base shear is reduced from 64.6 tons to 53.8 tons. . This reduction rate is equivalent to $17 \%$. As a result, use of friction damper reduces mean of $14 \%$ in base shear of the structure.

2) Considering the results it is found that installation of damper in upper level reduces displacements in all occurring earthquakes and shows better performance. This reduction in displacements is between 8 and 19\%. In case of using damper, the highest displacements have been recorded for empty tank.

3) Considering the above diagram, general trend of displacement is descending and this value has been reduced from $14.5 \mathrm{~cm}$ for installation of damper in foundation level to $12.3 \mathrm{~cm}$ for installation of damper in upper level. This reduction is equivalent to $15 \%$. Hence, it is found that the best performance when the tank is empty, friction damper is installed in the upper level.

4) Considering the results, general trend of displacement is descending and this value has been reduced from 12.1 $\mathrm{cm}$ for installation of damper in foundation level to $11.2 \mathrm{~cm}$ for installation of damper in upper level. This reduction is equivalent to $7 \%$. Hence, it is found that the best performance when the tank is full by $30 \%$, friction damper is installed in the upper level.

5) Based on the results in $60 \%$ of fullness of tank, it is observed that general trend of displacement is descending and this value has been reduced from $12.7 \mathrm{~cm}$ for installation of damper in foundation level to $10.8 \mathrm{~cm}$ for installation of damper in upper level. This reduction is equivalent to $15 \%$. Hence, it is found that the best performance when the tank is full by $60 \%$, friction damper is installed in the upper level.

6) Based on the results in $100 \%$ of fullness of tank, it is observed that general trend of displacement is descending and this value has been reduced from $10.7 \mathrm{~cm}$ for installation of damper in foundation level to $8.7 \mathrm{~cm}$ for installation of damper in upper level. This reduction is equivalent to $18.7 \%$. Hence, it is found that the best performance when the tank is full by $100 \%$, friction damper is installed in the upper level.

7) Base shear value without damper has direct relationship with reduction of water volume in tank and has descending trend. This reduction of base shear value is averagely $20 \%$.

8) When damper is not used, general trend of displacements in level of water tank is such that displacement is reduced with increasing fullness of the tank. Of course, this trend is approximate and it is observed that the lowest displacement occurs for fullness of $60 \%$ in case damper is not used. Displacement fluctuates between 25.7 $\mathrm{cm}$ and $15.7 \mathrm{~cm}$ from empty state to fullness state of $100 \%$; therefore, fullness of the tank reduces displacement by $40 \%$.

9) Recommendations for Further Studies

Studying effect of other dampers on behavior of water tanks and also studying effect of dampers in other tanks with different materials such as metal, composite

Studying potential failure modes in water elevated tanks and also modeling in tanks with braced frame or moment and braced frame and studying effect of using friction damper in metal tank with braced system

\section{References}

[1] Guide of exploitation and storage of water tanks , Publication No. 137, Plan and Budget Organization, Ministry of Energy

[2] Rules and criteria of the project and calculating groundwater tank, Publication No. 123, Plan and Budget Organization

[3] Seismic analysis of concrete elevated tanks with cylindrical bases considering dynamical interaction of structure, fluid and bedrock , Amin Ebrahimi Moghadam , Amir Abdollah Almola, Earthquake Engineering and Seismology Conference, December 2009

[4] Studying seismic vulnerability of metal elevated tank of Ardabil Tohid Estate with frame base as case study with finite elements method by applying structure and fluid interaction, Amir Jahazi, Hamzeh Roohi, Hamid Poor Bagheri, the first international conference on impermeable concretes and drinking water tanks, Guilan , Iran, February 2010 
[5] Studying effect of Vertical acceleration of earthquake on response of elevated fluid tanks with friction pendulum system resistant against uplift, Montazer Rabie, the third international conference on seismic strengthening, Tabriz, Iran, 2002 Base isolation of structures, Design guideline, July 2001.

[6] A.El Damatty, Studies on the Application of Tuned Liquid Dampers (TLD) to Up-Grade the Seismic Resistance of Structures, Ph.D., P. Eng, Assistant Professor Department of Civil and Environmental Engineering, the University of Western Ontario, April 2002

[7] Kobori, T. and Minai, R., Analytical study on active seismic response control, Transactions, Architectural Institute of Japan, 66, 257, 1960.

[8] Yao, J.T-P., Concept of structural control, ASCE Journal of Structural Division, 98, 1567, 1972.

[9] Kobori, T., Seismic-response-controlled structure with active mass driver system, part 1 design and part 2 verification, Earthquake Engineering and Structural Dynamics, 20, 133, 1991.

[10] Liu, S.C., Tomizuka, M., and Ulsoy, A.G., Challenges and opportunities in the engineering of intelligent systems, Smart Structures and Systems, 1, 1, 2005.

[11] American Society of Civil Engineers (ASCE), Minimum Design Loads for Buildings and Other Structures (ASCE-7), 1995, 1998, 2002 and 2005 Editions, Reston, Virginia.

[12] Naeim, F. and Kelly, J. M., Design of Seismic Isolated Structures: From Theory to Practice, JohnWiley \& Sons, Inc., New York, 1999.

[13] Kawashima, K. et al., Effectiveness of the variable damper for reducing seismic response of highway bridges, in Proceedings of Second USJapan Workshop on Earthquake Protective Systems for Bridges, PWRI, Tsukuba Science City, Japan, 1992, p. 479.

[14] Kelly, T.E., Base Isolation of Structures, Design Guidelines, Holmes Consulting Group Ltd., Wellington, New Zealand, 2001.

[15] Pall, A.S. and Marsh, C., Response of friction damped braced frames, ASCE, Journal of Structural Division, $108,1313,1982$.

[16] Pall, A. et al., Friction dampers for seismic control of Canadian Space Agency headquarters, Earthquake Spectra, 9, 547, 1993.

[17] Cheng, F.Y. and Tian, P., Assessment of algorithms, material nonlinearity, and foundation effects on structural control of seismic structures, in Proceedings of International Symposium on Public Infrastructure System Research, Choi, C.K. and Penzien, J. (eds.), KoreaAdvanced Institute of Science andTechnology, Seoul, Korea, 1995, p. 211. 